\title{
Antibiotics alone in the treatment of appendicitis
}

\author{
Ameer Farooq MD MPH, Francois Rouleau-Fournier MD MSc, Carl Brown MD MSc
}

Cite as: CMAJ 2021 May 25;193:E769. doi: 10.1503/cmaj.202777

1 Many patients with acute uncomplicated appendicitis can be treated with antibiotics alone

The incidence of acute appendicitis is estimated to be 75 per 100000 population per year, with the highest incidence in patients aged $10-19$ years. ${ }^{1}$ Overall, $67 \%$ of cases are nonperforated. ${ }^{1}$ The findings of recent randomized controlled trials (RCTs) suggest that as many as $71 \%$ of patients with a first presentation of uncomplicated appendicitis could be treated with antibiotics alone, although other studies have suggested that $40 \%$ of conservatively treated acute appendicitis will require surgery within 5 years. ${ }^{2,3}$

2 Antibiotic treatment alone is not for all patients

Antibiotic treatment alone is not suggested for children, older adults or patients who are pregnant, or for patients with sepsis or who are immunocompromised (Table 1). . $^{1,3,4}$

\section{3}

Patients with complicating features on imaging are more likely to go on to require operative treatment Computed tomography is suggested to identify patients with complicating features (Table 1). ${ }^{2,3}$ Fecaliths convey a 2-fold higher recurrence within 90 days. ${ }^{2,3}$

4 Initial antibiotic treatment should be with intravenous (IV) for at least 24 hours

Patients undergoing nonoperative treatment should receive IV antibiotics in hospital for 24-72 hours to monitor for worsening pain or clinical deterioration. ${ }^{2,3} \mathrm{~A}$ common regimen is IV ceftriaxone for 24 hours followed by $5-10$ days of ciprofloxacin and metronidazole. Other regimens consistent with current guidelines for intraabdominal infection may be used. ${ }^{5}$

\section{- All patients with appendicitis should be examined and counselled by a surgeon}

Five-year data from the Appendicitis Acuta RCT in Finland suggest a $40 \%$ recurrence rate (even in the absence of a fecalith). ${ }^{3}$ Appendectomy remains a safe operation with low morbidity. ${ }^{2}$ Patients with appendicitis who receive treatment with antibiotics will require appropriate imaging or endoscopic follow-up. Surgeons should discuss these considerations with patients to determine their preference for treatment in a shared decision-making process.
Table 1: Complicating clinical and radiologic features in appendicitis

Clinical feature
- Signs of sepsis or shock
- Peritonitis
- Immunocompromise
- Pregnancy
- Children (<18 yr)
- Older adults (>60 yr)

Radiologic feature

- Fecalith

- Abscess

- Phlegmon

- Free ascites

- Free air

- Neoplasm

\section{References}

1. Al-Omran M, Mamdani MM, McLeod R. Epidemiologic features of acute appendicitis in Ontario, Canada. Can J Surg 2003;46:263-8.

2. CODA Collaborative; Flum DR, Davidson GH, Monsell SE, et al. A randomized trial comparing antibiotics with appendectomy for appendicitis. N Engl J Med 2020;383:1907-19.

3. Salminen P, Tuominen R, Paajanen $\mathrm{H}$, et al. Five-year follow-up of antibiotic therapy for uncomplicated acute appendicitis in the APPAC randomized clinical trial [published erratum in JAMA 2018;320:1711]. JAMA 2018;320:1259-65.

4. Huang L, Yin $Y$, Yang L, et al. Comparison of antibiotic therapy and appendectomy for acute uncomplicated appendicitis in children: a meta-analysis. JAMA Pediatr 2017;171:426-34.

5. Mazuski JE, Tessier JM, May AK, et al. The Surgical Infection Society revised guidelines on the management of intra-abdominal infection. Surg Infect (Larchmt) 2017;18:1-76.

\section{Competing interests: None declared.}

This article has been peer reviewed.

Affiliation: St. Paul's Hospital, Section of Colorectal Surgery, Department of Surgery, University of British Columbia, Vancouver, BC

Content licence: This is an Open Access article distributed in accordance with the terms of the Creative Commons Attribution (CC BY-NC-ND 4.0) licence, which permits use, distribution and reproduction in any medium, provided that the original publication is properly cited, the use is noncommercial (i.e., research or educational use), and no modifications or adaptations are made. See: https://creativecommons. org/licenses/by-nc-nd/4.0/

Correspondence to: Carl Brown, CBrown@ providencehealth.bc.ca 